Z. klin. Chem. u. klin. Biochem.

8. Jg., S. 582-587, Novernber 1970

\title{
Spezifische Kreatininbestimmung im Serum
}

\author{
Von E. KNoli und D. Stamm \\ Aus dem Max-Planck-Institut für Psychiatrie, München
}

(Eingegangen am 21. Mai 1970)

Das Verfahren von Owen, Iggo, Scandrett und Stewart (1) zur Serum-Kreatininbestimmung nach Adsorption des Kreatinins an LLOYD's Reagenz (gereinigte Fullererde) wurde modifiziert und auf das Mikrolitersystem Eppendorf adaptiert. Die Adsorption des Kreatinins unter verschiedenen Bedingungen wurde untersucht und die Adsorptionsisotherme bei $22^{\circ}$ bestimmt. Der Einfluß von 10 Jaffépositiven Substanzen wurde geprüft, doch konnte keine Veränderung des Kreatininwertes festgestellt werden. Es gelingt also mit dieser Methode, das , wahre“ Kreatinin zu bestimmen. Für ein Kollektiv von 63 Männern und 55 Frauen haben wir den Normalbereich für das Serumkreatinin angegeben. Die Prüfung auf Alters- und Geschlechtsabhängigkeit ergab bei den Frauen einen signifikant geringeren Kreatininwert als bei den Männern. Das Verfahren zeichnet sich durch gute Präzision und hohe Spezifität aus. Die Einfachheit und Schnelligkeit der Methode sowie ihre geringe Störanfälligkeit lassen sie besonders für Routinebestimmungen geeignet erscheinen.

\section{The specific determination of serum creatinine}

The method of OWEn, IGgo, SCANDRETt and STEWART (1) for the determination of serum creatinine after adsorption of the creatinine onto LLOYD's reagent (purified FULLER's earth) was modified and adapted for the Eppendorf microlitre system. The adsorption of creatinine under different conditions was studied and the adsorption isotherm was determined at $22^{\circ}$. The influence of $10 \mathrm{Jaffe}-$ positive substances was tested, but they were without effect on the measured creatinine value. This method therefore determines the ,true "creatinine. The normal range for serum creatinine was determined for a collective of 63 men and 55 women. Tests on age and sex dependence showed a significantly lower creatinine value for women than for men. The method is precise and shows a high specificity. From the simplicity and speed of the method as well as the freedom from interference, it appears especially suitable for routine determinations.

Die heute gebräuchlichen Methoden zur Kreatininbestimmung beruhen fast ausschließlich auf der 1886 von JAFFÉ entdeckten Reaktion des Kreatinins mit alkalischer Pikratlösung (2). Hierbei bildet sich ein roter Farbstoff, dessen Absorption gemessen wird. Die Struktur des Farbstoff's wurde erst kürzlich näher untersucht, sowie allgemeine Reaktionsbedingungen hierbei geprüft (3). Ein Nachteil der Jaffé-Reaktion ist allerdings ihre geringe Spezifität. Eine Anzahl von Substanzen, die sogenannten Pseudokreatinine bzw. Nichtkreatininchromogene, ergeben mit alkalischem Pikrat ein ähnliches Reaktionsprodukt wie Kreatinin und verursachen einen erhöhten ,scheinbaren“ Kreatininwert. Es wurden deshalb zahlreiche Modifikationen der Jaffe'schen Farbreaktion vorgeschlagen, die alle zum Ziel hatten, ihre Spezifität zu erhöhen. Erwähnt seien hier die Oxydation der Störsubstanzen mit Jod $(4,5)$ bzw. ihre Zerstörung durch Cer-(IV)-sulfat (6,7), oder ihre Abtrennung durch Äther-Extraktion (8), weiterhin die Abtrennung des Kreatinins mit Kalignost $(9,10,11)$, sowie die JafféReaktion vor und nach enzymatischer Zerstörung des Kreatinins $(12,13,14)$ und die „fading fraction“Methode (15).

Doch konnte keine dieser Methoden, auf die routinemäßige Serumkreatininbestimmung angewandt, voll befriedigen. Entweder war das Probevolumen zu groß, der Aufwand an Zeit und Arbeit zu umfangreich, oder die Spezifität und Präzision ließen zu wünschen übrig. Wir haben versucht, ein Verfahren zu entwickeln, das all diesen Erfordernissen gerecht wird. Hierzu haben wir das Kreatinin durch Adsorption an Fullererde abgetrennt. Dieses Reagenz wurde erstmals 1935 von Bor- sook (16) zur Kreatininbestimmung benutzt. Von zahlreichen Autoren wurde diese Methode in der Folgezeit aufgegriffen $(1,17-24)$, wurde jedoch für die tägliche Routine als zu aufwendig erachtet (25). Durch Anpassung an das Mikrolitersystem Eppendorf und Modifizierung einiger. Reaktionsschritte gelang es, diese Nachteile zu beseitigen.

\section{Methodik}

Das im folgenden beschriebene Verfahren zur Bestimmung von Kreatinin im Serum ist eine Modifikation des Verfahrens von OweN und Mitarbeitern (1). Als Ausgangsmenge werden $400 \mu \mathrm{l}$ Blutserum eingesetzt. Die Proteine werden mit Wolframat/Schwefelsäure ausgefällt. Der pH-Wert im Serumfiltrat beträgt etwa 1,1. Nach dem Abzentrifugieren des Eiweißniederschlags wird das Kreatinin in saurer Lösung an LLOYD's Reagenz (gereinigte Fullererde) adsorbiert. Die Nichtkreatininchromogene verbleiben hierbei in Lösung und können bei der folgenden Jaffé-Reaktion mit alkalischer Pikratlösung nicht meht stören. Bereis nach 1-2 Min. hat sich das Adsorptionsgleichgewicht eingestellt und die Fullererde kann abzentrifugiert werden. Nach dem Verwerfen der überstehenden Lösung wird mit alkalischer Pikratlösung des Kreatinin von der Fullererde desorbiert und gleichzeitig bildet sich der rote Farbstoff. Nach etwa 20 Min. wird die Extinktion der Lösung . gegen den Reagenzienleerwert bei $509 \mathrm{~nm}$ gemessen.

\section{Apparate and Geräte}

1. Mikrolitersystem Eppendorf $3000^{1}$ ), einschl. Marburg Pipetten, Mikrozentrifuge, Rüttler zum Mischen, Mikromix mit Platinrührer, Pipettenspitzen und Reaktionsgefäße.

2. MT-2 Küvetten, $d=2 \mathrm{~cm}$ und $d=1 \mathrm{~cm}^{2}$ )

3. Eppendorf-Photometer mit Cadmium-Lampe und Filter $509 \mathrm{~nm}^{1}$ ) oder Spektralphotometer PM Q II²).

1) Eppendorf-Gerätebau, Netheler u. Hinz GmbH, Hamburg 2) Firma Carl Zeiss, Oberkochen/Württemberg 


\section{Reagenzien}

Wenn nicht besonders vermerkt, wurden p. a. Reagenzien der Firma Merck, Darmstadt, benutzt.

1. Pikrinsäure-Lösung 1,2 proz. : $9,0 \mathrm{~g}$ Pikrinsäure (mit etwa $50 \%$ Wasser angefcuchtet, bezogen auf dic Trockensubstanz) werden unter leichtem Erwärmen in $500 \mathrm{ml}$ demin. Wasser gelöst. Die Lösung wird durch ein Faltenfilter filtriert und in einer braunen Flasche aufbewahrt.

2. $0,75 \mathrm{~N} \mathrm{NaOH}$

3. Kreatinin-Standard:

Stammlösung: $50 \mathrm{mg}$ Kreatinin $/ 100 \mathrm{~m} / 0,1 \mathrm{~N} \mathrm{HCl}$

Arbeitslösung: $1: 100$ Verdünnung mit demin. Wasser $=0,5 \mathrm{mg}$ Kreatinin $/ 100 \mathrm{ml}$.

Die Kreatinin-Stammlösung ist bei $+4^{\circ}$ unbeschränkt stabil, während der Arbeitsstandard jede Woche neu angesetzt werden sollte.

4. Gesätt. wäßr. Oxalsäurelösung

5. Fullererde-Suspension ${ }^{3}$ ), 10proz. in Wasser

6. $\mathrm{Na}_{2} \mathrm{WO}_{4}, 10$ proz. in Wasser

7. $0,53 \mathrm{~N} \mathrm{H}_{2} \mathrm{SO}_{4}$

\section{Arbeitsweise}

$400 \mu l$ Serum werden in ein Mikroreaktionsgefäß Eppendorf pipettiert und mit $500 \mu l$ demin. Wasser verdünnt. Dazu gibt man $200 \mu l$ 10proz. Natriumwolframatlösung und $500 \mu l$ 0,53 N Schwefelsäure. Nun wird mit dem Rüttler etwa 30 Sek. geschüttelt und danach mit der Tischzentrifuge bei $15000 \mathrm{~g} 1 \mathrm{Min}$. zentrifugiert. $500 \mu l$ vom klaren Uberstand werden in ein zweites Reaktionsgefäß pipettiert und mit $500 \mu l$ Wasser verdünnt. Nach Żusatz von $100 \mu \mathrm{l}$ gesätt. Oxalsäurelösung und $200 \mu \mathrm{l}$ FullererdeSuspension wird wieder $1 \mathrm{Min}$. auf dem Rüttler geschüttelt. Während dieser Zeit wird das Kreatinin an der Fullererde adsorbiert. Es sollte nicht weniger als $1 \mathrm{Min}$. geschüttelt werden, da in diesem Falle die Gefahr besteht, daß sich das Adsorptionsgleichgewicht noch nicht vollständig eingestellt hat. Die Suspension wird nun $1 \mathrm{Min}$. zentrifugiert, und der klare Uberstand wird verworfen. Es folgt nun die eigentliche Jaffé-Reaktion. $\mathrm{Zu}$ der abzentrifugierten Fullererde gibt man nacheinander $500 \mu l$ Wasser, $200 \mu l$ Pikrinsäurelösung und $200 \mu l 0,75 \mathrm{~N}$ Natronlauge. Anschließend wird sofort die fest am Boden haftende Fullererde mit dem Mikromix aufgewirbelt, bis eine homogene Verteilung in der Lösung vorliegt.

Die so entstandene Suspension wird $10 \mathrm{Min}$. geschüttelt. Nach dem Schütteln wird $1 \mathrm{Min}$. zentrifugiert, und mindestens $20 \mathrm{Min}$. nach Zugabe der Natronlauge wird bei $509 \mathrm{~nm}$ die Extinktion gegen den Reagenzienleerwert gemessen. Im Reagenzienleerwert werden statt der $500 \mu l$ Serumfiltrat $500 \mu l$ demin. Wasser eingesetzt.

Die Extinktionsmessung kann sowohl mit einem EppendorfPhotometer mit Cadmium-Lampe und Filter $509 \mathrm{~nm}$ als auch mit dem Spektralphotometer PM Q II der Firma Carl Zeiss durchgeführt werden. (Bandbreite bei dem letzteren Gerät 0,5-0,7 nm, Verstärkung 10/I/I.)

\section{Berechnung}

Die Auswertung erfolgt über 2 wäßr. Kreatininstandards, die bei jeder Versuchsserie mitgeführt werden. In Analogie zum-Reagenzienleerwert werden $500 \mu l$ des Arbeitsstandards statt des Serumfiltrats durch den Analysengang gezogen.

Der Kreatiningehalt einer unbekannten Probe errechnet sich wie folgt:

$\mathrm{E}=$ Extinktion

$$
c_{p}=\frac{E_{p}}{E_{s}} \cdot c_{s}
$$

$c=$ Konzentration des Kreatinins in $\mathrm{mg} / 100 \mathrm{ml}$

Indices: $\mathrm{p}=$ Probe

$$
\mathrm{s}=\text { Standard }
$$

$\mathrm{Da}_{\mathrm{a}} \mathrm{c}_{\mathrm{s}}=0,5 \mathrm{mg} / 100 \mathrm{~m} /$, und unter Berücksichtigung der Tatsache, daß das Serum beim Enteiweißen 1:4 verdünnt wird, ergibt sich:

$$
c_{p}=\frac{E_{p}}{E_{B}} \cdot 2 .
$$

3) Scrva Entwicklungslabor Heidelberg

\section{Zuverlässigkeitskriterien}

\section{Präzision}

Täglich wird eine Kontrollprobe in Doppelbestimmungen mitanalysiert. Aus 37 Analysen an 37 Tagen wurden die Streuung von Tag zu Tag und aus den Doppelbestimmungen die Streuung in der Serie berechnet. Die Ergebnisse dieser statistischen Qualitätskontrolle sind in Tabelle 1 zusammengefaßt.

Tab. 1

Ergebnisse der Qualitätskontrolle der Serumkreatininbestimmung

\begin{tabular}{lcc}
\hline & $\begin{array}{c}\text { Streuung in } \\
\text { der Serie }\end{array}$ & $\begin{array}{c}\text { Streuung von } \\
\text { Tag zu Tag }\end{array}$ \\
\hline$\overline{\mathbf{X}}($ in $\mathrm{mg} / 100 \mathrm{ml})$ & 0,73 & 0,73 \\
$\mathbf{s}($ in $\mathrm{mg} / 100 \mathrm{ml})$ & 0,008 & 0,014 \\
$\mathrm{VK}($ in $\%$ ) & 1,1 & 2,0 \\
\hline Anzahl $\mathrm{n}$ & 37 Doppelbest. & 37 Einzelbest. \\
\hline
\end{tabular}

\section{Ricbtigkeit}

Die Richtigkeit wurde durch Ermittlung der Wiederauffindungsrate überprüft.

a) Wäßr. Kreatininlösungen: Eine wäßr. Kreatininlösung von $1 \mathrm{mg}$ Kreatinin $/ 100 \mathrm{~m} l$ wurde mit $0,4 \mathrm{bzw}$. $0,8 \mathrm{mg}$ Kreatinin $/ 100 \mathrm{ml}$ aufgestockt. Die Wiederauffindungsrate betrug 98,3 bzw. $100 \%$ (Mittelwerte aus Dreifachbestimmungen).

b) Blutseren von 10 Normalpersonen wurden mit je $1 \mathrm{mg}$ Kreatinin $/ 100 \mathrm{ml}$ aufgestockt. Wiedergefunden wurden im Mittel 97,8\% (s=1,5\%).

c) 10 lipämische Blutseren wurden ebenfalls mit je $1 \mathrm{mg}$ Kreatinin $/ 100 \mathrm{ml}$ aufgestockt. Die Wiederauffindungsrate betrug in diesem Fall 99,1\% ( $s=2,3 \%)$.

\section{Nacbweisgrenze}

Die Nachweisgrenze, berechnet aus der $3 s_{\mathrm{L}}$-Grenze der Streuung der Reagenzienleerwerte in der Serie (26), liegt bei $0,02 \mathrm{mg}$ Kreatinin $/ 100 \mathrm{ml}$.

\section{Sperifität}

Die Spezifität des Verfahrens, insbesondere der Einfluß von Störsubstanzen, wird im Kapitel „Prüfung der Methode" ausführlich diskutiert.

\section{Prüfung der Methode Enteiveißung}

Bei der Enteiweißung mit Wolframat/Schwefelsäure ist darauf zu achten, daß der $\mathrm{pH}$-Wert des Serumfiltrats $<2$ ist, denn bei größeren $\mathrm{pH}$-Werten wird das Kreatinin z. T. am ausgefällten Eiweiß adsorbiert (1). In der vorliegenden Arbeit ist das Mengenverhältnis Wolframat/ Schwefelsäure so gewählt worden, daß nur die Hälfte der Schwefelsäure zur Freisetzung der Wolframsäure verbraucht wird; im Serumfiltrat ergibt sich so im Mittel ein $\mathrm{pH}$-Wert von 1,1 .

Das Serum wird beim Enteiweißen durch die Fällungsreagenzien 1:4 verdünnt. Mit Hilfe von Kreatinin$\left[1-^{14} \mathrm{C}\right]^{4}$ ) (spezif. Aktivität $76 \mu \mathrm{C} / \mathrm{mg}$ ) wurde bewiesen, daß nach dem Ausfällen des Eiweißes und Zentrifugieren das Kreatinin in dem Gesamtvolumen von 1,6 m/ gleich-

4) Lieferfirma: The Radiochemical Centre, Amersham 
verteilt ist: $400 \mu l$ eines Kontrollserums wurden nach Zusatz von $100 \mu l$ Kreatinin-[1-14 $\mathrm{C}$-lösung (etwa 50000 Imp./Min.) enteiweißt. Nach dem Zentrifugieren wurde in $500 \mu l$ des Uberstandes unter Verwendung des Szintillators nach Hayes $^{5}$ ) mit dem Tri-Carb Liquid Scintillation Spectrometer Modell $3375^{6}$ ) die ${ }^{14} \mathrm{C}$-Aktivität gemessen. Aus 10 Einzelwerten ergab sich ein Mittelwert von $31,38 \%$; dies entspricht, auf das Gesamtvolumen von $1,6 \mathrm{~m} l$ ungerechnet, $100,4 \%$.

Es wurde die Frage geprüft, ob der wäßr. KreatininStandard und der Reagenzienleerwert wie das Serum mit den Enteiweißungsreagenzien behandelt werden müssen. Unter Berücksichtigung der Verdünnung (1:4) beim „Enteiweißen“" ergab sich jedoch für die wäßrige Kreatininlösung unter dem Einfluß von Wolframat/Schwefelsäure die gleiche Eichkurve wie ohne diese Reagenzien. Im Analysengang kann deswegen auf diesen Schritt verzichtet werden, d. h. der Kreatinin-Standard bzw. der Leerwert (demin. Wasser) können wie das Serumfiltrat direkt zur Adsorption an der Fullererde eingesetzt werden.

\section{Adsorption des Kreatinins an Fullererde}

Fast alle Autoren, die das Fullererde-Verfahren benutzt haben, vertreten die Ansicht, daß das Kreatinin in saurer Lösung vollständig an der Fullererde adsorbiert wird. Erstmals wies Beyermann (10) darauf hin, daß die Ausbeute an Kreatinin bei der Abtrennung mit Fullererde durchschnittlich nur $95 \%$ beträgt.

Ein Anzeichen für die unvollständige Adsorption des Kreatinins ist die Tatsache, daß bei wäßr. Kreatininlösungen die Steigung der Eichkurve beim FullererdeVerfahren um 9,5\% geringer ist als beim direkten JafféVerfahren. Die Vermutung liegt nahe, daß die Ursache hierfür in einer unvollständigen Adsorption des Kreatinins an der Fullererde zu suchen ist. Wir haben deshalb diese Frage eingehend unter Verwendung von Kreatinin- $\left[1-{ }^{14} \mathrm{C}\right]$ geprüft. Bei den folgenden Experimenten werden $100 \mu l$-Kreatinin-[1-14 C]-lösung von etwa 50000 Imp./Min. eingesetzt. Unter Berücksichtigung der spezif. Aktivität der Substanz $(76 \mu \mathrm{C} / \mathrm{mg})$ und der Zählausbeute des Meßgerätes ( $90 \%$ ) entspricht dies $0,33 \mu \mathrm{g}$ Kreatinin.

Um zu ermitteln, wieviel Kreatinin unter den oben beschriebenen Bedingungen des Trennungsganges an der Fullererde adsorbiert wird, werden jeweils $500 \mu l$ inaktive Kreatininlösung verschiedener Konzentration mit $100 \mu l$-Kreatinin- $\left[1-{ }^{14} \mathrm{C}\right]$-lösung versetzt, und nach $\mathrm{Zu}$ gabe von $400 \mu l$ demin. Wasser, $100 \mu l$ gesätt. Oxalsäurelösung und $200 \mu l 10$ proz. Fullererde-Suspension 1-2 Min. geschüttelt und zentrifugiert. Der Überstand wird vollständig abpipettiert, und seine ${ }^{14} \mathrm{C}$-Aktivität wird gemessen. Die Ergebnisse sind in Tabelle 2 zusammengefaßt.

Die in Tab. 2 angegebenen Werte sind Mittelwerte aus je 5 Einzelbestimmungen. Im Durchschnitt bleiben also $7,6 \%$ des Kreatinins in der Lösung.

5) Packard Technical Bulletin Nr 1

6) Firma Packard Instruments
Tab. 2

Proz. Adsorption von Kreatinin an Fullererde bei verschiedenen Kreatininkonzentrationen

\begin{tabular}{lccc}
\hline & trägerfrei & $\begin{array}{c}0,5 \mathrm{mg} \text { inakt. } \\
\text { Kreatinin } / 100 \mathrm{ml} \\
=2,5 \rho \mathrm{g}\end{array}$ & $\begin{array}{c}1 \mathrm{mg} \text { inakt. } \\
\text { Kreatinin } / 100 \mathrm{ml} \\
=5 \mu \mathrm{g}\end{array}$ \\
\hline $\begin{array}{l}\% \text { Kreatinin } \\
\text { in Lösung } \\
\%\end{array}$ & 7,8 & 7,4 & 7,7 \\
$\begin{array}{l}\% \text { Kreatinin } \\
\text { adsorbiert }\end{array}$ & 92,2 & 92,6 & 92,3 \\
\hline
\end{tabular}

Führt man das gleiche Experiment wie oben beschrieben (Vergleich direktes Jaffé-Verfahren gegen FullererdeVerfahren) unter Zusatz von Kreatinin- $\left[1-{ }^{14} \mathrm{C}\right]$ durch, mißt aber statt der Extinktion der alkal. KreatininPikratlösung die ${ }^{14} \mathrm{C}$-Aktivität in jeweils $0,5 \mathrm{~m} l$ der gefärbten Lösung, so ergibt sich auch hier ein um 8,3\% höherer Wert beim direkten Jaffé-Verfahren (Ergebnisse aus Dreifachbestimmungen). Aus dem Vergleich dieser Werte mit denen aus Tabelle 2 geht hervor, daß die niedrigeren Werte beim Fullererde-Verfahren ausschließlich auf unvollständige Adsorption des Kreatinins zurückzuführen ist, daß hingegen die Desorption des Kreatinins bzw. des Kreatinin-Pikrats in alkalischer Lösung vollständig ist. Dies steht im Widerspruch zu den Angaben von Loken (21).

Abhängigkeit der Adsorption von der Oxalsäurekonzentration Zunächst wurde die Adsorption des Kreatinins an Fullererde ohne Oxalsäurezusatz sowohl trägerfrei, als auch bei verschiedenen Konzentrationen an inaktivem Kreatinin untersucht. Die Ergebnisse sind in Tabelle 3 dargestellt.

Tab. 3

Adsorption des Kreatinins an Fullererde ohne Oxalsäurezusatz

\begin{tabular}{lccc}
\hline & trägerfrei & $\begin{array}{c}0,5 \mathrm{mg} \text { inakt. } \\
\text { Kreatinin/100 ml }\end{array}$ & $\begin{array}{c}1 \mathrm{mg} \text { inakt. } \\
\text { Kreatinin } / 100 \mathrm{ml}\end{array}$ \\
\hline $\begin{array}{l}\text { \% Kreatinin } \\
\text { in Lösung }\end{array}$ & 44,4 & 71 & 76,7 \\
\% Kreatinin & 55,6 & 29 & 23,3 \\
\hline
\end{tabular}

Ohne Oxalsäurezusatz ist die Adsorption des Kreatinins also unvollständig.

Die folgende Tabelle 4 zeigt die Abhängigkeit der Adsorption von der Oxalsäurekonzentration bei konstanter inaktiver Kreatininlösung von 0,5 mg Kreatinin $/ 100 \mathrm{ml}$.

Tab. 4

Abhängigkeit der Adsorption des Kreatinins an Fullererde von der Oxalsäurekonzentration

\begin{tabular}{lccccccc}
\hline $\begin{array}{l}\mu l \text { gesätt. Oxal- } \\
\text { säurelösung }\end{array}$ & 0 & 80 & 100 & 120 & $\ldots 160$ & 200 \\
\hline $\begin{array}{l}\text { \% Kreatinin } \\
\text { adsorbiert }\end{array}$ & 29 & 91,6 & 91,5 & 91,5 & 90,6 & 90 \\
\hline
\end{tabular}

Wie aus Tabelle 4 hervorgeht, ist es am günştigsten, die Kreatininadsorption an der Fullererde mit einem Zusatz von $100 \mu l$ gesätt. Oxalsäurelösung durchzuführen, da im Bereich von 80-120 $\mu l$ Oxalsäurelösung die proz. adsorbierte Kreatininmenge konstant bleibt. Ferner wird bei höheren Oxalsäurekonzentrationen weniger Kreatinin an der Fullererde adsorbiert. 


\section{Adsorptionsisotberme}

Um festzustellen, wieviel $\mu \mathrm{g}$ Kreatinin maximal pro mg Fullererde adsorbiert werden, haben wir die Adsorptionsisotherme bei $22^{\circ}$ gemessen. Um mit der Kreatininlösung leichter in den Bereich der Sättigungsadsorption zu kommen, haben wir statt der 10 proz. nur eine 0,5 proz. Fullererde-Suspension verwendet. $200 \mu l$ der 0,5 proz. Fullererde-Suspension entsprechen so gerade $1 \mathrm{mg}$ Fullererde. Zu $500 \mu l$ inaktiver Kreatininlösung (variable Konzentration) werden $100 \mu \mathrm{l}$-Kreatinin-[1-14 C]-lösung, 400 $\mu l$ demin. Wasser, $100 \mu l$ gesätt. Oxalsäurelösung und $200 \mu l$ 0,5 proz. Fullererde-Suspension gegeben. Bis zur Einstellung des Adsorptionsgleichgewichtes wird etwa 2 Min. geschüttelt und danach 1 Min. zentrifugiert. Der Ubberstand wird vollständig abgehoben und seine Zählrate gemessen. Die hieraus resultierende KreatininGleichgewichtskonzentration $c_{\mathrm{gl}}$ wird graphisch als Funktion von $n_{a}$ ( $\mu$ Mol Kreatinin adsorbiert/mg Fullererde) dargestellt. $n_{a}$ ergibt sich aus der Differenz der zugegebenen Gesamtaktivität und der gemessenen Aktivität der Lösung. Die zur Adsorption eingesetzte Gesamtkreatininmenge (aktiv + inaktiv) variierte von $1,4 \mu \mathrm{g}$ bis $600 \mu \mathrm{g}(0,012 \mu \mathrm{Mol}-5,31 \mu \mathrm{Mol})$.

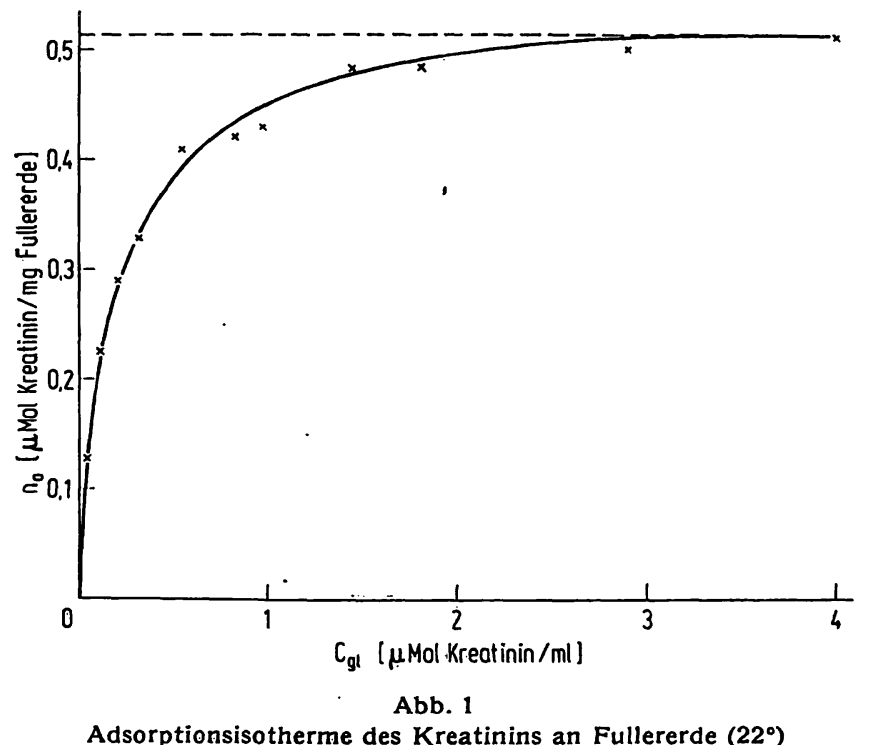

Aus Abbildung 1 ergibt sich die pro mg Fullererde maximal adsorbierbare Kreatininmenge zu $0,513 \mu \mathrm{Mol}$ $=58 \mu \mathrm{g}$ Kreatinin. In der zu Beginn dieser Arbeit beschriebenen Arbeitsweise werden etwa $20 \mathrm{mg}$ Fullererde zur Adsorption des Kreatinins von $0,5 \mathrm{ml}$ Serumfiltrat eingesetzt. Nimmt man als obere Grenze des Normalbereichs von Serumkreatinin $1,1 \mathrm{mg} / 100 \mathrm{ml}$, so wären in $0,5 \mathrm{ml}$ Serumfiltrat max. $1,4 \mu \mathrm{g}$ Kreatinin enthalten, $20 \mathrm{mg}$ Fullererde können aber $1,16 \mathrm{mg}$ (also fast das $10^{3}$ fache) adsorbieren.

\section{Zeitabbängigkeit der Adsorption}

Um zu ermitteln, wie groß die Zeitdauer bis zur Einstellung des Adsorptionsgleichgewichts ist, werden wäßrige Lösungen konstanten Kreatiningehaltes verschieden lange mit Fullererde geschüttelt. Nach dem Entwickeln des roten Farbstoffs und dem Abzentrifugieren
Tab. 5

Abhängigkeit der Adsorption von der Schütteldauer a) bei reinen Kreatininlösungen

\begin{tabular}{lccccccc}
\hline $\begin{array}{l}\text { Schütteldauer } \\
\text { in Min. }\end{array}$ & 10 & 8 & 6 & 4 & 2 & 1 & 10 Sek. \\
$\begin{array}{l}\text { Extinktion } \\
\text { der Lösung }\end{array}$ & 0,082 & 0,082 & 0,081 & 0,080 & 0,081 & 0,079 & 0,073 \\
\hline
\end{tabular}

b) bei Serumfiltrat

$\begin{array}{lcc}\text { Schütteldauer in Min. } & 10 & 1 \\ \text { Extinktion der Lösung } & 0,086 & 0,084\end{array}$

der Fullererde wird die Extinktion des Überstandes gemessen.

Es zeigt sich, daß bei reinen Kreatininlösungen erst bei Verkürzung der Adsorptionszeit auf 10 Sek. ein Extinktionsabfall von $10 \%$ zu verzeichnen ist. Nach 1-Min.Schüttelzeit hat sich das Adsorptionsgleichgewicht sowohl bei reinen Kreatininlösungen als auch bei Serumfiltraten vollständig eingestellt. In der Praxis schütteln wir die Standards und Serumfiltrate jeweils 1-2 Min., statt der bisher üblichen $10 \mathrm{Min}$. (27).

\section{Spezifität der Metbode}

Von den folgenden Stoffen wird in der Literatur berichtet, daß sie eine positive Jaffé-Reaktion zeigen: Aceton (28), Brenztraubensäure (6, 7), Ascorbinṣäure (4), Fructose (29), Glucose (28), 4-Aminohippursäure (18), 2-Oxoglutarsäure, $\beta$-Hydroxybuttersäure, Hydantoin und Harnsäure (30). Wir haben den störenden Einfluß all dieser Substanzen untersucht. Ein Kontrollserum wird hierzu mit drei verschiedenen Konzentrationen der betreffenden Störsubstanz aufgestockt. Der Kreatiningehalt des Kontrollserums sowie der aufgestockten Proben wird dann nach der eingangs der Arbeit beschriebenen Methode bestimmt.

Tabelle 6 zeigt, daß bei keiner der die eigentliche Farbreaktion störenden Substanzen mit der hier beschriebenen Methode eine Störung zu beobachten ist. Die Pseudokreatinine verbleiben also bei der Kreatininadsorption an der Fullererde quantitativ in Lösung, oder werden nur $\mathrm{zu}$ einem so geringen Teil adsorbiert, daß dies bei der Farbreaktion nicht meßbar in Erscheinung tritt. Durch Einschaltung des Adsorptionsschrittes an der Fullererde gelingt folglich mit der an sich unspezifischen Jaffé-Reaktion eine Bestimmung des „wahren" Kreatiningehaltes des Serums.

\section{Wabl der geeigneten Meßsuellenlänge}

Das Adsorptionsmaximum der alkalischen Kreatininpikratlösung liegt bei $485 \mathrm{~nm}$. Es ist jedoch nicht $\mathrm{zu}$ empfehlen, die Extinktionsmessung bei dieser Wellenlänge durchzuführen, da bci $485 \mathrm{~nm}$ die alkalische Pikratlösung des Reagenzienleerwertes ebenfalls eine sehr starke Absorption zeigt. Dies macht sich in einer erhöhten Nachweisgrenze und einer schlechteren Präzision des Verfahrens bemerkbar. Verschiedentlich wurde auch vorgeschlagen, mit der $\mathrm{Hg}$-Linie $546 \mathrm{~nm}$ zu messen. Hier ist die Absorption des Reagenzienleerwertes zwar verschwindend klein, aber die Absorption des alkalischen Kreatininpikrats ist zu gering. 
Tab. 6

Einfluß von Störsubstanzen auf die Kreatininbestimmung. Die unter Einfluß von Storsubstanzen auf die Kreating sind Normalwerte der den Substanzen angegebenen zitiert nach Documenta Geigy, Wissenbetr. Substanz im Serum, zitiert (1), sowie Plenert/Heine: Normalschaftliche Tabellen, 7. Aufl., 1968 (1), sowie Plenert/Heine: Nors werte, VEB Verlag Volk und

\begin{tabular}{|c|c|c|c|c|}
\hline & \multicolumn{4}{|c|}{$\begin{array}{l}\text { mg Kreatinin } / 100 \mathrm{ml} \text { gefunden, be } \\
\text { einem Aufstockzusatz an Störsub- } \\
\text { stanz zu (in mg/100 ml) }\end{array}$} \\
\hline & 0 & 1 & 5 & 10 \\
\hline $\begin{array}{l}\text { Aceton } \\
0,23-0,35 \mathrm{mg} / 100 \mathrm{ml}(1)\end{array}$ & 0,78 & 0,79 & 0,79 & 0,78 \\
\hline $\begin{array}{l}\mathrm{L}(+) \text {-Ascorbinsäure } \\
0,2-1,4 \mathrm{mg} / 100 \mathrm{ml}(1)\end{array}$ & 0,71 & 0,70 & 0,71 & 0,71 \\
\hline $\begin{array}{l}\text { Na-Pyruvat } \\
0,3-1,0 \mathrm{mg} / 100 \mathrm{ml}(1)\end{array}$ & 0,71 & 0,71 & 0,71 & 0,72 \\
\hline 4-Aminohippursäure & 0,78 & 0,78 & 0,78 & 0,79 \\
\hline $\begin{array}{l}\text { 2-Oxoglutarsäure } \\
0,5-2,1 \mathrm{mg} / \mathrm{l} \text { Vollblut (1) }\end{array}$ & 0,78 & 0,78 & 0,80 & 0,78 \\
\hline $\begin{array}{l}\beta \text {-Hydroxybuttersäure } \\
1,4-17,1 \mathrm{mg} / l \text { Vollblut (1) }\end{array}$ & 0,78 & 0,77 & 0,78 & 0,77 \\
\hline Hydantoin & 0,78 & 0,78 & 0,79 & 0,79 \\
\hline
\end{tabular}

b)

$\mathrm{mg}$ Kreatinin $/ 100 \mathrm{ml}$ gefunden, bei einem Aufstockzusatz an Störsub$\operatorname{stanz} \mathrm{zu}$ (in $\mathrm{mg} / 100 \mathrm{ml}$ )

$0 \begin{array}{lll}\operatorname{stanz} \mathrm{zu} & (\mathrm{in} \mathrm{mg} / 100 \mathrm{ml} & 25\end{array}$

\begin{tabular}{|c|c|c|c|c|}
\hline $\begin{array}{l}\mathrm{D} \text { (-)-Fructose } \\
10 \mathrm{mg} / 100 \mathrm{ml}(2)\end{array}$ & 0,71 & 0,67 & 0,69 & 0,69 \\
\hline
\end{tabular}

c)

mg Kreatinin/100 $\mathrm{ml}$ gefunden, bei einem Aufstockzusatz an Störsubstanz zu (in $\mathrm{mg} / 100 \mathrm{ml}$ )

$\begin{array}{llll}0 & 6 & 12 & 24\end{array}$

\begin{tabular}{llllll}
\hline Harnsäure \\
$(1,9-8,7 \mathrm{mg} / 100 \mathrm{ml})(1)$ & 0,78 & 0,77 & 0,79 & 0,78 \\
\hline
\end{tabular}

\section{d)}

\begin{tabular}{lcccccc}
\hline & \multicolumn{6}{c}{$\begin{array}{c}\text { mg Kreatinin/100 } \mathrm{ml} \text { Kefunden, bei einem } \\
\text { Aufstockzusatz an Störsubstanz zu } \\
\text { (in mg/100 ml) }\end{array}$} \\
& 0 & 200 & 350 & 500 & 1000 \\
\hline $\begin{array}{l}\text { a-D-Glucose } \\
(61-130 \mathrm{mg} / 100 \mathrm{ml})(1)\end{array}$ & 0,71 & 0,70 & 0,70 & 0,70 & 0,72 \\
\hline
\end{tabular}

Als Kompromiß bietet sich die Cd-Linie $509 \mathrm{~nm}$ an. Die Extinktion des roten Kreatininfarbstoffs bei dieser Wellenlänge ist groß genug, um mit ausreichender Empfindlichkeit und Präzision gemessen werden zu können; während der Reagenzienleerwert relativ klein ist. Die Eichkurve ist bis mindestens $5 \mathrm{mg}$ Kreatinin/ $100 \mathrm{ml}$ linear (in reinen Lösungen, in 1-cm-Küvetten gemessen), dies entspricht $16 \mathrm{mg}$ Kreatinin $/ 100 \mathrm{ml}$ Serum. Wir haben die Messung in 2-cm-Küvetten durchgeführt und bei zu hohen Kreatiningehalten in einem zweiten Ansatz nach dem Enteiweißen das Serumfiltrat 1:5 verdünnt. Sowohl in dem Eppendorf-Photometer als auch in dem Filterphotometer PL 4 der Firma Carl Zeiss kann die $\mathrm{Hg}$-Lampe leicht gegen eine Cd-Lampe ausgetauscht werden; die Cd-Filter $509 \mathrm{~nm}$ sind bei den bez. Firmen erhältlich. Bei Verwendung eines Spektralphotometers (PM Q II der Firma C. Zeiss) wurden die gleichen Ergebnisse erhalten.

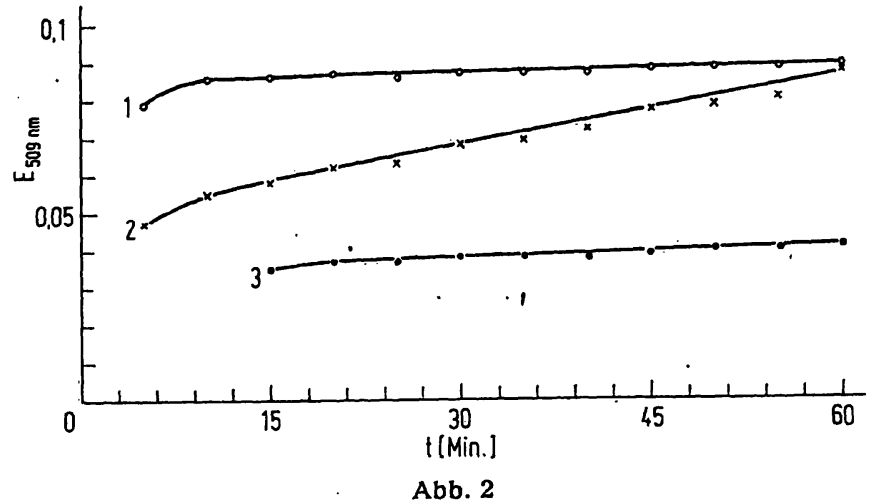

Zeitabhängigkeit der Farbstoffentwicklung

Kurve 1: Reine wåßrige Kreatininlösung

Kurve 2: 0,4 ml Kontrollserum: Direkte Jaffé-Reaktiọn ohne Fullererde-Ads.

Kurve 3: 0,4 ml Kontrollserum: Fullererde-Verfahren

\section{Zeitabbängigkeit der Farbstoffentwicklung}

In Abbildung 2 ist die Zeitabhängigkeit der Farbstoffentwicklung graphisch dargestellt. Für reine Kreatininlösungen ist die Farbstoffbildung nach $10 \mathrm{Min}$. abgeschlossen und bleibt danach konstant (Kuve 1). Kurve 2 zeigt den zeitlichen Verlauf der Extinktion bei der direkten Jaffé-Reaktion (ohne Adsorption) mit einem Serumfiltrat. Sie zeigt einen stetigen, recht starken Anstieg der Extinktion, der selbst nach $60 \mathrm{Min}$. noch anhält. Hierfür sind die Nichtkreatininchromogene verantwortlich, deren Farbstoff sich langsamer entwickelt als der des Kreatinins (27). Bei dieser Methode ist man also an eine sehr exakte Einhaltung der Zeitabstände gebunden. In Kurve 3 ist der zeitliche Extinktionsverlauf beim Fullererde-Verfahren dargestellt. Die Farbstoffbildung ist nach $20 \mathrm{Min}$. abgeschlossen, und danach steigt die Extinktion nur noch sehr geringfügig. Dies hat eine wichtige praktische Konsequenz: Man ist nach Ablauf von 20 Min. nicht mehr an eine exakte Zeiteinhaltung angewiesen und kann selbst $60 \mathrm{Min}$. nach Zugabe des alkal. Pikrats noch den gleichen Kreatininwert erhalten wie nach 20 Min. Dies zeigt Tabelle 7: Nach Zugabe der alkalischen Pikratlösung wurde $20 \mathrm{Min}$. geschüttelt und

a) sofort zentrifugiert und nach verschied. Zeiten gemessen

b) zunächst verschieden lange stehen gelassen und erst kurz vor der Extinktionsmessüng zentrifugiert.

Es ist dadurch möglich, eine größere Serie (bis zu 50 Blutseren gleichzeitig) zu analysieren und in jedem Stadium die Analyse einige Zeit zu unterbrechen, ohne eine Fehlbestimmung zu machen. Dies macht die hier beschriebene Methode besonders geeignet für ein Routinelaboratorium.

Tab. 7

Zur Zeitabhängigkeit der Farbstoffbildun Die Tabellenwerte bedeuten $\mathrm{mg}$ Kreatinin/100 $\mathrm{ml}$

\begin{tabular}{lcccc}
\hline $\begin{array}{l}\text { Zeit nach Zugabe der } \\
\text { alkal. Pikratlösung }\end{array}$ & 20 Min. & 30 Min. & 40 Min. & 50 Min. \\
\hline $\begin{array}{l}\text { direkt nach d. Schütteln } \\
\text { zentrifugiert. }\end{array}$ & 0,84 & 0,87 & 0,79 & 0,85 \\
$\begin{array}{l}\text { kurz vor der Ext.- } \\
\text { messung zentrifug. }\end{array}$ & 0,84 & 0,78 & 0,85 & 0,85 \\
\hline
\end{tabular}

:

Z. klin. Chem. u. klin. Biochem. / 8. Jahrg. 1970 / Heft 6 


\section{Normalwerte}

Es wurde der Kreatiningehalt im Blutserum von 55 gesunden Frauen und 63 Männern im Alter zwischen 16 und 60 Jahren bestimmt. Das Blut wurde zwischen $7^{30}$ und $10^{30}$ Uhr entnommen. Die Werte sind weder normal noch logarithmisch normal verteilt; als Kenngrößen für das Kollektiv wurden deshalb Median und 96 Percentil gewählt. In Tabelle 8 sind die Werte des von uns ermittelten Normalbereiches für den Serumkreatiningehalt zusammengefaßt.

Diese Werte zeigen gute Úbereinstimmung mit denen, die gleichfalls mit Methoden bestimmt wurden, die nur das "wahre Kreatinin“ erfassen (31).

Die Alters- und Geschlechtsabhängigkeit wurde geprüft. Während sich keine signifikante Altersabhängigkeit fest-
Tab. 8

Normalbereich für den Kreatiningehalt des Serums

\begin{tabular}{lcc}
\hline Kollektiv & $\begin{array}{c}\text { Median } \\
(\mathrm{mg} / 100 \mathrm{ml})\end{array}$ & $\begin{array}{c}96 \text { Percentil } \\
(\mathrm{mg} / 100 \mathrm{ml})\end{array}$ \\
\hline $\begin{array}{l}\text { Männer } \\
\mathrm{n}=63\end{array}$ & 0,82 & $0,64-1,05$ \\
$\begin{array}{l}\text { Frauen } \\
\mathrm{n}=55\end{array}$ & 0,68 & $0,56-0,91$ \\
Gesamt & 0,74 & $0,57-1,05$ \\
$\mathrm{n}=118$ & & \\
\hline
\end{tabular}

stellen. ließ, ergaben sich bei den Frauen signifikant niedrigere Kreatininwerte als bei den Männern $(P<0,01)$.

Fräulein B. HaRTMANN haben wir für ihre gewissenhafte Mitarbeit herzlich zu danken.

\section{Literatur}

1. Owen, J. A., B. Iggo, F. J. Scandrett und C. P. Stewart, Biochem. J. 58, 426 (1954). - 2. JAFFÉ, M., Hoppe-Seyler's Z. physiol. Chem. 10, 391 (1886). - 3. SeELIG, H. P., diese Z. 7, 581 (1969). - 4. TAussKY, H. H., J. biol. Chemistry 208, 853 (1954). 5. TAussky, H. H., in: Standard Methods of Clinical Chemistry, Vol. 3, ed. D. Seligson, Academic Press, N. Y. p. 99, (1961). 6. KostrR, J. V., und V. RABeK, Biochim. biophysica Acta (Amsterdam) 5, 210 (1950). - 7. KostrR, J. V., und J. SonkA, Biochim. biophysica Acta (Amsterdam) 8, 86 (1952). - 8. TAusskY, H. H., Clin. chim. Acta (Amsterdam) 1, 210 (1956). - 9. BeYERmanN, K., Clin. chim. Acta (Amsterdam) 17, 47 (1967). - 10. BeyermanN, K., W. GeroK und U. Groth, Klin. Wschr. 45, 950 (1967). - 11. BexermanN, K., Z. analyt. Chem. 205, 416 (1964). 12. Dubos, R., und B. F. Mrller, J. biol. Chemistry 121, 429 (1937). - 13. Miller, B. F., und R. Dubos, J. biol. Chemistry 121, 457 (1937). - 14. Milier, B. F., und R. Dubos, J. biol. Chemistry 121, 447 (1937). - 15. Sror, C., Scand. J. Clin. Laborat. Invest. 17, 381 (1965). - 16. Borsook, H., J. biol. Chemistry 110, 481 (1935). -
17. Fisher, R. B., und A. E. Wilhelmi, Biochem. J. 31, 1131 (1937). - 18. HAre, R. S., Proc. Soc. exp. Biol. Med. 74, 148 (1950). - 19. Lauson, H. D., J. Appl. Physiol. 4, 227 (1951). - 20. Haugen, H. N., und E. M. Blegen, Scand. J. Clin. Laborat. Invest. 5, 67 (1953). - 21. LoKEN, F., Scand. J. Clin. Laborat. Invest. 6, 325 (1954). - 22. Edwards, K. D. G., und H. M. Whyte, Australian J. Exp. Biol. Med. Sci. 36, 383 (1958). - 23. Doolan, P. D., E. L. Alpen und G. B. Theil, Amer. J. Med. 32, 65 (1962). 24. Husdan, H., und A. Rapoport, Clin. Chem. (New York) 14, 222 (1968). - 25. Schirmeister, J., H. WillmanN und H. Kiefer, Klin. Wschr. 41, 878 (1963). - 26. KArSER, H., Z. analyt. Chem. 209, 1 (1965). - 27. HENry, R. J., Clinical Chemistry, Harper \& Row, New York 1964, p. 287. - 28. HaugeN, H. N., Scand. J. Clin. Laborat. Invest. 6, 17 (1954). - 29. PAGET, M., Gontier, M., und J. Liefooghe, Ann. Biol. Clin. 13, 535 (1955). - 30. Kanturek, V., V. Pacovsky, und J. Sonka, Casopis Lekaru Ceskych 93, 435 (1954). - 31. Dubach, U. C., J. Metz und P. Schmid, Klin. Wschr. 45, 621 (1967).
Priv.-Doz. Dr. Dr. D. Stamm 8000 München 23 Kraepelinstr. 10 